\title{
Açık Arazi Koşullarında Kızılçam (Pinus brutia Ten.) Tohumlarının Fidan Gelişimi ve Fidan Yüzdesi Üzerine Bazı Nanopartikül Uygulamalarının Etkisi
}

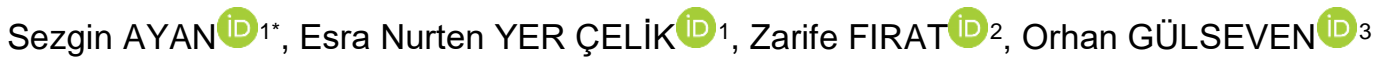 \\ ${ }^{1}$ Kastamonu Üniversitesi, Orman Fakültesi, Kastamonu \\ ${ }^{2}$ Mersin Orman Bölge Müdürlüğü, Gülnar Orman İşletme Müdürlüğü, Mersin \\ ${ }^{3}$ Kastamonu Üniversitesi, Fen Bilimleri Enstitüsü, Kastamonu \\ Geliş Tarihi (Received): 20.05.2021, Kabul Tarihi (Accepted): 27.06.2021 \\ $\square$ Sorumlu Yazar (Corresponding author*): sezginayan@gmail.com \\ (C) +903662801701 등 +903662152316
}

ÖZ

Nanoteknolojik gelişmelere paralel olarak günümüzde nanopartiküllerin ortamlardaki konsantrasyonları gittikçe artmaktadır. Çevre üzerindeki etkileri yeterince bilinmeyen bu materyallerin tanınması ve etkilerinin tespiti önem arz etmektedir. Bu çalışma, Kızılçamın (Pinus brutia Ten.) ana yayılış sahası dışında bulunan doğal kızılçam meşceresinde gerçekleştirilmiştir. Yarı kurak iklimin hâkim olduğu Ankara-Beypazarı yöresinde; Silika, $\mathrm{Fe}_{2} \mathrm{O}_{3}, \mathrm{Fe}_{3} \mathrm{O}_{4}, \mathrm{ZnO}$, $\mathrm{TiO}_{2}, \mathrm{Au}, \mathrm{CuO}$ ve Ag nanopartiküllerinin (NPs) beş farklı doz seviyesinde (çok yüksek, yüksek, orta, düşük, çok düşük) açık alan koşullarında çimlendirilen tohumlarının fidan gelişimi ve fidan yüzdesi parametrelerine etkisi araştırılmıştır. Üç tekrarlı kurulan denemede elde edilen fidan boyu (FB), kök boğazı çapı (KBÇ) ve fidan yüzdesine (FY) ait verilere varyans analizi ve Duncan testi uygulanmıştır. Araştırma sonucunda; NP çeşit ve doz faktörleri ile her iki faktörün etkileşimi $F B, K B C ̧$ ve $F Y$ üzerinde \%95 güven düzeyinde anlamlı farklılık oluşturmuştur. NP çeşit ve dozları 1+0 yaşlı kızılçam FB ve KBÇ gelişimi ile FY üzerinde olumsuz etki yapmıştır. Buna karşılık, kontrol fidanlarının boy ve çap gelişimi ile FY değerlerinin daha yüksek olduğu tespit edilmiştir. Kontrol işlemi fidanlarının ortalama $\mathrm{FB}$ değeri, $\mathrm{Fe}_{2} \mathrm{O}_{3}$ NP uygulaması boy değerlerine göre \%35 yüksek, KBÇ değeri ise Cu NP uygulamasına göre \%70 civarında daha yüksek olduğu tespit edilmiştir.

Anahtar Kelimeler: Fidan morfolojisi, fidan yüzdesi, kızılçam, nanopartikül

\section{Effects of Some Nanoparticle Applications on Seedling Growth and Percentage of Brutian Pine (Pinus brutia Ten.) in Open Field Conditions}

\begin{abstract}
In parallel with nanotechnological developments, the concentrations of nanoparticles in environments are increasing today. It is important to recognize and determine the effects of these materials, whose effects on the environment are not sufficiently known. This research was carried out in a natural stand of brutian pine (Pinus brutia Ten.), outside its natural distribution area. In Ankara-Beypazarı province, where the semi-arid climate is dominant; the effects of silika, $\mathrm{Fe}_{2} \mathrm{O}_{3}, \mathrm{Fe}_{3} \mathrm{O}_{4}, \mathrm{ZnO}, \mathrm{TiO}_{2}, \mathrm{Au}, \mathrm{CuO}$, and $\mathrm{Ag}$ nanoparticles (NPs) with five different application doses (very high, high, medium, low, very low) on seedling percentage and growth of germinated brutian pine seeds were investigated in open area conditions. Data of seedling percentage (SP), height (SH), and root collar diameter (RCD) were subjected to analysis of variance and Duncan's multiple range test. result of the research showed that the types and doses of the Np and their interactions made a significant difference on SH, RCD, and SP at 95\% significant level. All types and doses of NP negatively affected the SP, SH, and RCD of $1+0$ year-old brutian pine seedlings. It was determined that
\end{abstract}


these values of the control seedlings were higher than other treatments. The average $\mathrm{SH}$ value of the control seedlings was $35 \%$ higher than those of the $\mathrm{Fe}_{2} \mathrm{O}_{3} \mathrm{NP}$ application, $\mathrm{RCD}$ was found to be around $70 \%$ higher than those of the Cu NP application.

Keywords: Seedling morphology, seedling percentage, Brutian pine, nanoparticle

\section{Giriş}

Son yıllarda nanoboyutlu malzemelerle ilgili çalışmalar başı başına yeni bir bilim alanı olma yolunda çok önemli gelişmeler göstermektedir. Nanopartiküller (NPs), nanokristaller, nanotüpler, nanoteller, nanoçubuklar veya nano ince filmler gibi farklı sınıflardaki malzemelerin temel ortak özelliği nanoboyutlu olması yani boyutunun 100 nanometrenin $(\mathrm{nm})$ altındaki partiküller olmasıdır (Miller ve ark., 2004; Rao ve ark., 2005; Gürmen ve Ebin, 2008). Roco (2011) ise NPs'i 100 nm küçük olan mükemmel fiziksel ve kimyasal özelliklere sahip parçacıklar olarak tanımlamakta ve doğada yarattığı etkilerin oldukça farklı olabildiğini vurgulamaktadır. Özellikle, NPs'in yüksek yüzey/hacim oranı, elektronik yapısı, ara yüzey reaktivitesi gibi belirgin derecede farklı fizikokimyasal özellikleri son derece farklı çevresel davranışlara ve etkilere sebep olabileceği düşünülmektedir (Ma ve Wang, 2010). Ayrıca, hem halihazırda doğada bulunması hem de nanoteknolojinin gelişmesinin doğal bir sonucu olarak, NPs'in konsantrasyonlarının farklı doğal ortamlarda artması muhtemeldir (Üçünçü Tunca, 2015). Bununla birlikte; NPs'in büyük çoğunluğu çok düşük çözünürlüğe veya biyobozunurluğa sahiptirler ve biyolojik sistemlerde kolayca birikebilirler. Besin zincirinde biyobirikim ve biyodegredasyona maruz kaldığında ekotoksikolojik etkileri nedeniyle günümüzde yaşantımızı tehdit edici bir unsur olarak görülmektedir (Kuzma, 2008).

NPs sahip oldukları mekanik, manyetik ve kimyasal özellikleri sayesinde tıpta, elektronikte, ecza sektöründe, kozmetik üretimde, inşaat, takı yapımı ve optik sektörlerde, son yıllarda dünya çapında geniş uygulama alanı kazanmışlardır (Kaweeteerawat ark., 2015). Doğada kendiliğinden bileşen oluşturabilen NPs sanayide kullanım alanı bulması ile birlikte çevre üzerinde oluşturduğu konsantrasyonları artmaktadır. Son yıllarda endüstriyel birçok ürün içeriğinde de bileşen olarak kullanımı nanopartikülleri büyük bir ekonomi haline getirmektedir (Tunca, 2015). NPs toprak ile çevre arasındaki bağlantıyı kurma rolleri nedeniyle bitkiler üzerine yapılan araştırmalarda da yaygın olarak kullanılmaktadırlar. Ayrıca, bitkiler, toprak ve NPs arasındaki en önemli bileşendir, bu nedenle NPs'in taşınma mekanizması ve etkilerinin bilinmesi önem arz etmektedir (Du ve ark., 2011; Kundu ve ark., 2015).
Son yıllarda NPs'in kullanım alanları ziraat ve ormancılık alanlarında da önem kazanmıştır. NPs'in sebep olduğu farklı etkilerin düzeylerinin belirlenmesi, bu etkilerden pozitif yönde olanlarının bitki yetiştirme ve ıslah tekniklerinde destekleyici unsur olarak kullanılması, negatif yönde olanlarından ise bitkilerin bütün diğer canlı organizmalarda olduğu gibi korunması bakımından oldukça önemlidir. NPs tohumların çimlenme ve büyümesini etkileyen farklı potansiyel etkileri sebebi ile son dönemde yoğun talep görmektedirler (Aleksandrowicz-Trzcinska, 2019). Tarımsal ürünlerde istenmeyen tohum uyku halinin aksine, hızlı çimlenme ve büyüme intiyacı nedeniyle NPs'i içeren çalışmalar ve araştırmalar her geçen gün artmaktadır (Azura ve ark., 2017).

Arabidinopsis thalian (Cinisli ve ark., 2019), Beta vulgaris (Arslan, 2018), mısır ve çavdar (Ma ve ark., 2010), marul (Doğaroğlu ve Köleli, 2016) gibi zirai ürünlerin tohum çimlenmesi ve fidecik gelişimi üzerine NPs'in etkileri konusunda araştırmalara ulaşılabilirken, çok yıllık bitkilerde; Sarıçam (Çelikbaş, 2019) ve Karaçam (Tan Çelikbaş, 2019) tohum çimlenmesi ve fidecik gelişimleri üzerine; özellikle de orman ağaçlarında NPs'in etkileri neredeyse hiç araştırılmamış ve tespit edilmemiştir. Bu kapsamda, NPs'in öncelikle bitkilerin oluşum aşaması olan tohum çimlenmesi üzerindeki etkilerinin belirlenmesi büyük önem taşımaktadır. Bu çaIışmada; farklı NPs'in kızılçam doğal yayılış sahası dışındaki Beypazarı yöresindeki popülasyondan temin edilen tohumların fidan gelişimi ve fidan yüzdesi özellikleri üzerindeki olası etkilerinin neler olabileceği ve uygulamanın sınır dozlarının tespitinin belirlenmesi amaçlanmıştır. Böylece doğal orman ekosistemlerinde özellikle toprakta depolanan NPs'in çimlenme ortamında meydana getirdiği değişimlerin Türkiye'de çok geniş doğal yayılış alanı olan ve hızlı gelişen ağaç türü özelliğiyle yerli türler içerisinde en öne çıkan tür olan kızılçam (Pinus brutia Ten.) için belirlenmiş olacaktır. Özellikle endüstriyel faaliyetlerin var olduğu merkezlere yakın bölgelerde bulunan ormanları işletmekle yükümlü olan teknik ormancılara doğal ve yapay gençleştirme çalışmaları için ilk temel bilgilerin üretilmesine bu çalışmayla katkı sağlanabilecektir. 


\section{MATERYAL VE YÖNTEM}

Bu çalışmada; yaygın etkiye sahip olan NP çeşit ve dozlarının, açık arazi koşullarında kızılçam tohumlarının fidan gelişimi ve fidan yüzdesi üzerindeki etkileri araştırılmıştır.

\section{Materyal}

Uygulanmak istenen NP çeşit ve dozlarının fidan yüzdesi (FY) ve fidan boyu (FB) ile kök boğazı çapı (KBÇ) gelişimleri üzerine etkisini gözlemlemek üzere kızılçamın ana yayılış sahası dışındaki "kenar-marjinal" popülasyon olarak değerlendirilebilecek Ankara ili Beypazarı ilçesi Sekli köyü sınırlarındaki 505 numaralı bölmede gerçekleştirilmiştir. Güney bakılı, 1053 m rakımlı saha amenajman planında çalışma sahası Çzcd ${ }_{1}$ meşcere tipi ile sembolize edilmektedir (Şekil 1). Plan ünitesi, İç Anadolu Bölgesi'nden Batı Karadeniz ardına geçiş zonundadır. Beypazarı ilinin yıllık ortalama sıcaklığı $13,2^{\circ} \mathrm{C}$ 'dır. Yıllık ortalama yağış miktarı ise 423 mm'dir. Gerek yaz gerekse kış aylarında gece - gündüz sıcaklık farkları fazladır. Erinç iklim sınıflandırmasına göre yağış etkinlik indisi 20,74 olup, iklim tipi yarı kuraktır. Thornthwaite iklim sınıflandırmasına göre ise iklim sınıfı D, B'2,s,b'3 olarak tespit edilmiştir (D: Yarı Kurak, B'2: 2. Derece Mezotermal, s: Su fazlası kış mevsiminde ve orta derecede olan, b'3: Yaz buharlaşma oranı: \%55,6) (URL-1, 2021). Arazisinin tamamı volkaniktir. Toprak derinliği yer yer sığdan derin topraklara kadar değişmektedir (Fırat, 2020).

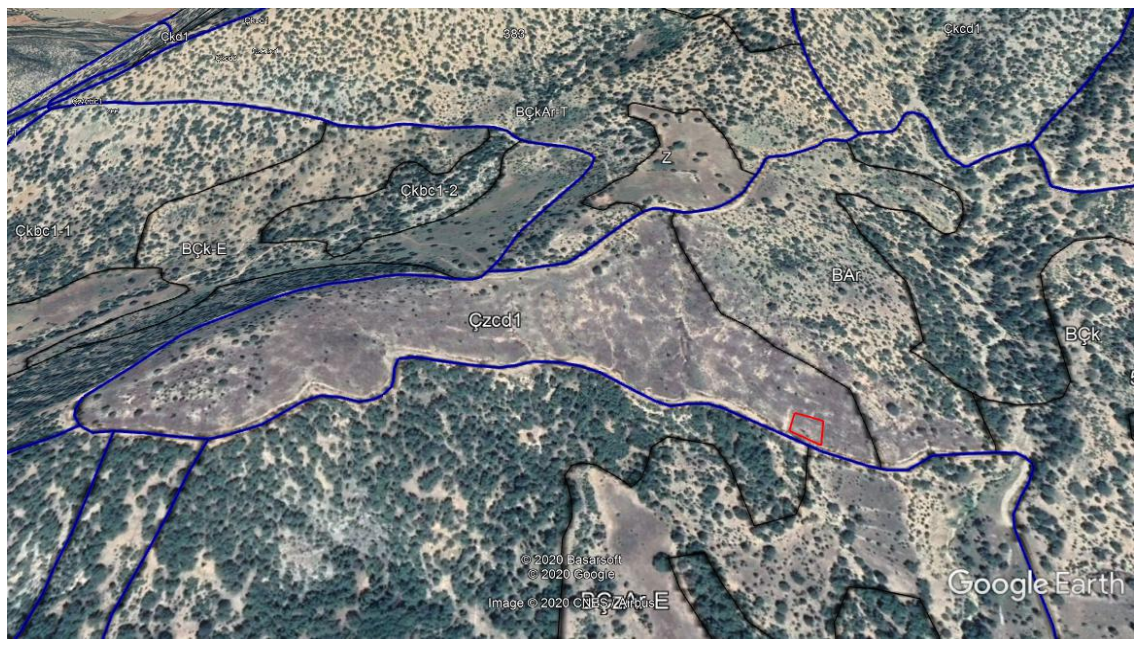

Şekil 1. Çalışma alanının konumu

Çalışmada kızılçam tohumlarına sekiz farklı NP çeşidi [Silika (Sigma-Aldrich/806765); Manyetit $\left(\mathrm{Fe}_{3} \mathrm{O}_{4}\right), \mathrm{Fe}_{2} \mathrm{O}_{3}$ (Sigma-Aldrich/900090); ZnO (Sigma-Aldrich/721077); $\mathrm{TiO}_{2}$ (Sigma-Aldrich/700339); Au (Sigma-Aldrich/334049); CuO (Sigma-Aldrich/544868); Ag (SigmaAldrich/730815)] beş değişik dozda uygulanmıştır. Uygulanan NP çeşit ve doz miktarları Tablo 1'de verilmiştir.

\section{Yöntem}

Çalışmada lokal kızılçam popülasyonu tohumları kullanılmış olup, tohumlar ekim öncesi sekiz saat saf su içerisinde soğuk ortamda bekletilmiştir. Dolu ve sağlıklı olduğu kabul edilen suyun dibine çökelmiş tohumlar çalışmada kullanılmıştır. Her işlemde 20 adet tohum olacak şekilde sekiz farklı NP çeşidi ve kontrol hariç beş değişik dozda uygulanan deneme üç tekrarlı olarak gerçekleştirilmiştir. Tohumlar, ekim öncesi arazide hazırlanmış olan
NP solüsyonları ile 30 dakika muamele edilmiş ve "Tesadüf blokları deneme deseni"ne göre araziye ekilmiştir. Alanın kontrolü ve izlemesinin kolaylaşması için tahta çıtalarla ekim parselleri ve bloklar birbirinden ayrılmıştır. Ekim işlemleri, 20 Şubat 2019 tarihinde gerçekleştirilmiş ve ilk çimlenmeler mayıs ayı ortasında başlamıştır. 7 Mart 2020 tarihi itibariyle kışı sağlıklı bir şekilde geçirebilen fidan sayısı tespit edilerek fidan yüzdeleri belirlenmiştir. Ayrıca, birinci vejetasyon dönemi sonu itibariyle fidan boyu ve kök boğaz çapı değerleri dijital kumpas yardımı ile ölçülmüştür.

\section{İstatistiksel Değerlendirmeler}

Çalışma konusu fidanların çap, boy ve yaşama yüzdesi değişkenleri üzerinde basit istatistikler yapılmıştır. Ayrıca, ölçümlenen değişkenler normal dağılıma yaklaştırılmak için "ArcSinüs, logaritmik ve karekök" dönüştürmeleri yapılmış, en iyi sonuç karekök dönüştürmesinde 
alınmış ve uygulanmıştır. Anlamlı farklılığın tespiti için varyans analizi uygulanmış, Duncan testi ile homojen gruplar belirlenmiştir. Farklı çeşit ve doz faktörlerinin ikili ve çoklu etkileşimlerinin değerlendirilmesi için "General
Linear Modelleme" kullanılmıştır. Verilerin tamamı IBM SPSS Statistic (ver.23) paket programı aracılığı ile analiz edilmiştir.

Tablo 1. Nanopartikül çeşitleri ve dozları

\begin{tabular}{|c|c|c|}
\hline NP çeşitleri & $\begin{array}{l}\text { NP doz se- } \\
\text { viyeleri }\end{array}$ & $\begin{array}{c}\text { NP dozları } \\
(\mathrm{mg} / \mathrm{l})\end{array}$ \\
\hline \multirow{5}{*}{$\begin{array}{l}\text { Silika } \\
\mathrm{Fe}_{2} \mathrm{O}_{3} / \text { Demir (III) oksit } \\
\mathrm{Fe}_{3} \mathrm{O}_{4} / \text { Magnetit } \\
\mathrm{ZnO} / C ̧ i n k o \text { Oksit }\end{array}$} & Çok yüksek & 2000 \\
\hline & Yüksek & 1600 \\
\hline & Orta & 1200 \\
\hline & Düşük & 800 \\
\hline & Çok düşük & 400 \\
\hline \multirow{5}{*}{$\begin{array}{l}\mathrm{TiO}_{2} / \text { Titanyum Oksit } \\
\mathrm{CuO} / \text { Bakır Oksit }\end{array}$} & Çok yüksek & 1000 \\
\hline & Yüksek & 800 \\
\hline & Orta & 600 \\
\hline & Düşük & 400 \\
\hline & Çok düşük & 200 \\
\hline \multirow{5}{*}{$\begin{array}{l}\text { Au/Altın } \\
\text { Ag/Gümüş }\end{array}$} & Çok yüksek & 100 \\
\hline & Yüksek & 80 \\
\hline & Orta & 60 \\
\hline & Düşük & 40 \\
\hline & Çok düşük & 20 \\
\hline
\end{tabular}

\section{BULGULAR VE TARTIŞMA}

Kızılçam tohumlarında sekiz farklı nanopatikül çeşidinin boy, kök boğazı çapı ve fidan yüzdesi üzerine etkilerine ait varyans analizi ve Duncan çoklu testi sonuçları Tablo 2 'de verilmiştir. NP çeşidi faktörünün $F B, K B C ̧$ ve $F Y$ üzerinde önemli etkisi olduğu tespit edilmiştir. Tablo 2'de verilen genel ortalama değerlere göre $F B, K B C ̧$ ve $F Y$ değişkenleri bakımından kontrol işlemi bütün NP uygulamalarından daha yüksek bulunmuştur. Diğer bir ifadeyle, NP uygulamalarının gerek fidan yüzdesi gerekse fidan boyu ve kök boğazı çapı üzerine olumsuz etkisi olduğu saptanmıştır. Kontrol grubu ve sekiz farklı NP çeşitleri arasında $\mathrm{TiO}_{2}$ ve $\mathrm{Ag}$ nanopartikülleri $\mathrm{FB}$ ve $\mathrm{KBÇ}$ bakımından, $\mathrm{TiO}_{2}$ ve $\mathrm{Fe}_{2} \mathrm{O}_{3}$ nanopartikülleri ise $\mathrm{FY}$ bakımından diğer uygulanan NP'lere göre daha yüksek değerlere sahiptir. Buna karşın, $\mathrm{FB}$ üzerinde $\mathrm{Au}, \mathrm{Fe}_{3} \mathrm{O}_{4}$ ve $\mathrm{Fe}_{2} \mathrm{O}_{3}, \mathrm{KBÇ}$ üzerinde $\mathrm{Cu}$, $\mathrm{FY}$ üzerinde ise $\mathrm{Au}$ nanopartüllerinin en olumsuz etkiyi gösterdiği belirlenmiştir. 
Açık Arazi Koşullarında Kızılçam (Pinus brutia Ten.) Tohumlarının Fidan Gelişimi ve Fidan Yüzdesi Üzerine Bazı Nanopartikül Uygulamalarının Etkisi

Tablo 2. NP çeşidinin fidan boyu $(\mathrm{mm})$, kök boğazı çapı $(\mathrm{mm})$ ve fidan yüzdesi $(\%)$ üzerine etkisine ait varyans analizi ve Duncan testi sonuçları

\begin{tabular}{|c|c|c|c|}
\hline \multirow[b]{2}{*}{ NP Çeşidi } & \multicolumn{3}{|c|}{ Aritmetik Ortalama $(\bar{X}) \pm$ Standart hata $\left(S_{\bar{x}}\right)$} \\
\hline & Fidan boyu (mm) & Kök Boğazı Çapı (mm) & Fidan yüzdesi (\%) \\
\hline KONTROL & $59,05 \pm 4,12 \mathrm{a}$ & $1,41 \pm 0,11$ a & $33,3 \pm 0,17$ a \\
\hline $\mathrm{TiO}_{2}$ & $52,65 \pm 1,62 b$ & $1,16 \pm 0,04 b$ & $23,65 \pm 3,67 a b$ \\
\hline SíLİKA & $52,02 \pm 1,82$ bc & $1,02 \pm 0,05 \mathrm{bc}$ & $18,66 \pm 4,00 \mathrm{bc}$ \\
\hline $\mathrm{Ag}$ & $53,76 \pm 2,0 \mathrm{~b}$ & $1,12 \pm 0,05 \mathrm{~b}$ & $16,31 \pm 2,87 \mathrm{bc}$ \\
\hline $\mathrm{Fe}_{3} \mathrm{O}_{4}$ & $45,71 \pm 1,57 \mathrm{~d}$ & $0,93 \pm 0,04 \mathrm{~cd}$ & $18,98 \pm 3,62 \mathrm{bc}$ \\
\hline $\mathrm{ZnO}$ & $48,52 \pm 1,59 \mathrm{bcd}$ & $0,94 \pm 0,03 \mathrm{~cd}$ & $13,98 \pm 2,59$ bc \\
\hline $\mathrm{Au}$ & $45,72 \pm 1,84 \mathrm{~d}$ & $1,01 \pm 0,05 \mathrm{bc}$ & $10,96 \pm 2,22 \mathrm{c}$ \\
\hline $\mathrm{Fe}_{2} \mathrm{O}_{3}$ & $43,90 \pm 1,2 \mathrm{~d}$ & $0,89 \pm 0,04 \mathrm{~cd}$ & $22,96 \pm 2,29 \mathrm{abc}$ \\
\hline $\mathrm{Cu}$ & $46,78 \pm 1,3 \mathrm{~cd}$ & $0,83 \pm 0,03 \mathrm{~d}$ & $19,96 \pm 3,67$ bc \\
\hline F değeri & 6,281 & 9,631 & 3,515 \\
\hline$P$ düzeyi & 0,000 & 0,000 & 0,034 \\
\hline
\end{tabular}

NP dozu faktörünün de FB, KBÇ ve FY, üzerinde önemli etkisi olduğu tespit edilmiştir. Genel olarak uygulanan NP dozlarının FB ve KBÇ üzerindeki olumsuz etkisi "çok düşük" konsantrasyondan "yüksek" konsantrasyona doğru artmıştır (Tablo 3). FY değişkeni üzerinde ise "Düşük" doz ile Kontrol işlemi aynı homojen grupta yer almıştır. Ancak, sekiz farkı NP çeşidi ile beş farkı NP dozu uygulamasının dolayısıyla 40 farklı işlemin genel ortalaması $F Y$ üzerinde dozların etkisinin net ifadesini mümkün kılmamıştır (Tablo 4).
Deneme kapsamındaki NP çeşit ve doz faktörlerinin birlikte etkileşimli etkileri incelendiğinde Tablo 4'de görüleceği üzere $\mathrm{FB}$ üzerinde " $\mathrm{Fe}_{3} \mathrm{O}_{4}$-Yüksek" işlem kombinasyonu en olumsuz etkiyi yaparken, "Silika-Çok yüksek" işlem kombinasyonunda en yüksek boy değeri elde edilmiştir. Hatta bu değer, aynı homojen gruptaki Kontrol işleminden daha yüksek bulunmuştur. İkili etkileşimlerin boy değerleri üzerindeki etkisini gösterir Tablo 4 incelendiğinde doz etkisinin, NP çeşidi ile birlikte FB ve KBÇ üzerinde ise olumsuz tesir " $\mathrm{Fe}_{3} \mathrm{O}_{4}$-Yüksek" ve "SilikaYüksek" işlem kombinasyonlarında tespit edilmiştir.

Tablo 3. NP dozunun fidan boyu $(\mathrm{mm})$, kök boğazı çapı $(\mathrm{mm})$ ve fidan yüzdesi (\%) üzerine etkisine ait varyans analizi ve Duncan test sonuçları

\begin{tabular}{lccc}
\hline \multirow{2}{*}{ NP Dozu } & \multicolumn{2}{c}{ Aritmetik Ortalama $(\overline{\mathbf{X}}) \pm$ Standart hata $\left(\mathbf{S}_{\overline{\mathbf{x}}}\right)$} \\
\cline { 2 - 4 } & Fidan boyu $(\mathbf{m m})$ & Kök boğaz çapı $(\mathbf{m m})$ & Fidan yüzdesi $(\%)$ \\
\hline KONTROL & $59,05 \pm 4,12 \mathrm{a}$ & $1,41 \pm 0,11 \mathrm{a}$ & $33,30 \pm 0,17 \mathrm{a}$ \\
\hline Çok düşük & $46,65 \pm 1,80 \mathrm{bc}$ & $0,96 \pm 0,05 \mathrm{c}$ & $8,52 \pm 0,77 \mathrm{c}$ \\
\hline Düşük & $49,58 \pm 0,95 \mathrm{bc}$ & $0,97 \pm 0,02 \mathrm{c}$ & $34,35 \pm 2,46 \mathrm{a}$ \\
\hline Orta & $48,90 \pm 1,49 \mathrm{bc}$ & $0,88 \pm 0,04 \mathrm{~cd}$ & $12,26 \pm 1,93 \mathrm{c}$ \\
\hline Yüksek & $44,76 \pm 1,22 \mathrm{c}$ & $0,80 \pm 0,03 \mathrm{~d}$ & $15,17 \pm 1,26 \mathrm{bc}$ \\
\hline Çok yüksek & $50,75 \pm 1,42 \mathrm{~b}$ & $1,20 \pm 0,03 \mathrm{~b}$ & $20,60 \pm 2,21 \mathrm{~b}$ \\
\hline F değeri & 4,88 & 2,739 & 2,182 \\
\hline$P$ düzeyi & 0,000 & 0,000 & 0,032 \\
\hline
\end{tabular}


Açık Arazi Koşullarında Kızılçam (Pinus brutia Ten.) Tohumlarının Fidan Gelişimi ve Fidan Yüzdesi Üzerine Bazı Nanopartikül Uygulamalarının Etkisi

Tablo 4. NP çeşit ve doz faktörlerinin ikili etkileşimleri

\begin{tabular}{|c|c|c|c|c|c|}
\hline \multicolumn{3}{|c|}{ Fidan boyu (mm) } & \multicolumn{3}{|c|}{ Kök boğaz çapı (mm) } \\
\hline Uygulama Dozları & $\bar{X} \pm S_{\bar{x}}$ & Gruplar & Uygulama Dozları & $\bar{X} \pm S_{\bar{x}}$ & Grupla \\
\hline $\mathrm{Fe}_{3} \mathrm{O}_{4}-\mathrm{Yüksek}$ & $37,390 \pm 2,89$ & $\mathrm{~h}$ & $\mathrm{Fe}_{3} \mathrm{O}_{4}-\mathrm{Yüksek}$ & $0,66 \pm 0,06$ & $\mathrm{i}$ \\
\hline Au-Yüksek & $39,650 \pm 3,45$ & gh & Silika-Yüksek & $0,66 \pm 0,1$ & $\mathrm{i}$ \\
\hline $\mathrm{Fe}_{2} \mathrm{O}_{3}$-Çok yüksek & $39,666 \pm 3,45$ & gh & Ag-Yüksek & $0,70 \pm 0,05$ & ii \\
\hline Cu-Çok düşük & $40,100 \pm 1,88$ & gh & Au-Çok düşük & $0,70 \pm 0,1$ & ii \\
\hline Cu-Orta & $41,680 \pm 3,55$ & fgh & $\mathrm{Fe}_{2} \mathrm{O}_{3}$-Orta & $0,71 \pm 0,12$ & $\mathrm{ii}$ \\
\hline Au-Düşük & $41,720 \pm 2,02$ & fgh & Cu-Orta & $0,74 \pm 0,02$ & hii \\
\hline Silika-Yüksek & $41,808 \pm 2,59$ & fgh & Au-Yüksek & $0,75 \pm 0,05$ & ghii \\
\hline ZnO-Orta & $42,240 \pm 2,74$ & fgh & $\mathrm{Fe}_{2} \mathrm{O}_{3}-\mathrm{Yüksek}$ & $0,75 \pm 0,06$ & ghıi \\
\hline $\mathrm{Fe}_{2} \mathrm{O}_{3}$-Çok düşük & $42,285 \pm 3,46$ & fgh & Ag-Orta & $0,76 \pm 0,14$ & ghıi \\
\hline Ag-Yüksek & $42,400 \pm 2,98$ & fgh & Au-Orta & $0,78 \pm 0,07$ & ghii \\
\hline $\mathrm{Fe}_{2} \mathrm{O}_{3}-\mathrm{Yüksek}$ & $43,209 \pm 3,28$ & efgh & Cu-Çok yüksek & $0,80 \pm 0,09$ & ghıi \\
\hline Au-Çok düşük & $43,300 \pm 1,35$ & efgh & ZnO-Orta & $0,80 \pm 0,12$ & ghii \\
\hline Cu-Çok yüksek & $43,388 \pm 1,88$ & efgh & $\mathrm{Fe}_{2} \mathrm{O}_{3}$-Çok düşük & $0,80 \pm 0,08$ & ghii \\
\hline Ag-Orta & $43,680 \pm 3,58$ & defgh & Cu-Düşük & $0,81 \pm 0,05$ & fghıi \\
\hline $\mathrm{Fe}_{3} \mathrm{O}_{4}$-Düşük & $44,296 \pm 1,97$ & defgh & Cu-Çok düşük & $0,82 \pm 0,08$ & fghii \\
\hline $\mathrm{TiO}_{2}$-Çok düşük & $45,275 \pm 5,03$ & cdefgh & ZnO-Çok düşük & $0,84 \pm 0,06$ & fghıi \\
\hline $\mathrm{Fe}_{2} \mathrm{O}_{3}$-Orta & $45,880 \pm 8,27$ & bcdefgh & $\mathrm{Fe}_{3} \mathrm{O}_{4}$-Düşük & $0,84 \pm 0,04$ & fghıi \\
\hline ZnO-Düşük & $46,866 \pm 2,62$ & bcdefgh & ZnO-Yüksek & $0,92 \pm 0,05$ & efghıi \\
\hline Au-Çok yüksek & $47,000 \pm 3,29$ & bcdefgh & Cu-Yüksek & $0,92 \pm 0,06$ & efghıi \\
\hline $\mathrm{Fe}_{2} \mathrm{O}_{3}$-Düşük & $47,495 \pm 2,22$ & bcdefgh & $\mathrm{Fe}_{2} \mathrm{O}_{3}$-Çok yüksek & $0,95 \pm 0,1$ & defghii \\
\hline Au-Orta & $48,428 \pm 4,45$ & bcdefgh & Au-Düşük & $0,96 \pm 0,08$ & defghii \\
\hline $\mathrm{Fe}_{3} \mathrm{O}_{4}$-Çok yüksek & $48,662 \pm 4,07$ & abcdefgh & Silika-Düşük & $0,98 \pm 0,06$ & cdefghii \\
\hline Cu-Yüksek & $48,663 \pm 2,65$ & abcdefgh & $\mathrm{Fe}_{3} \mathrm{O}_{4}$-Orta & $1,00 \pm 0,2$ & bcdefghıi \\
\hline Ag-Çok düşük & $48,800 \pm 7,43$ & abcdefgh & $\mathrm{TiO}_{2}$-Düşük & $1,00 \pm 0,05$ & bcdefghii \\
\hline $\mathrm{TiO}_{2}$-Düşük & $49,152 \pm 3,22$ & abcdefgh & ZnO-Çok yüksek & $1,00 \pm 0$ & bcdefghıi \\
\hline Cu-Düşük & $49,714 \pm 1,97$ & abcdefgh & $\mathrm{Fe}_{2} \mathrm{O}_{3}$-Düşük & $1,00 \pm 0,04$ & abcdefghıi \\
\hline Silika-Düşük & $50,166 \pm 2,25$ & abcdefgh & ZnO-Düşük & $1,01 \pm 0,03$ & abcdefghıi \\
\hline ZnO-Yüksek & $51,091 \pm 2,85$ & abcdefgh & $\mathrm{TiO}_{2}$-Orta & $1,02 \pm 0,06$ & abcdefghii \\
\hline $\mathrm{Fe}_{3} \mathrm{O}_{4}$-Çok düşük & $51,566 \pm 4,22$ & abcdefgh & Ag-Çok düşük & $1,02 \pm 0,08$ & abcdefghi \\
\hline Silika-Çok düşük & $51,700 \pm 00$ & abcdefgh & $\mathrm{Fe}_{3} \mathrm{O}_{4}$-Çok düşük & $1,08 \pm 0,09$ & abcdefghı \\
\hline $\mathrm{TiO}_{2}$-Orta & $51,838 \pm 2,39$ & abcdefgh & Silika-Orta & $1,13 \pm 0,29$ & abcdefgh \\
\hline $\mathrm{TiO}_{2}$-Yüksek & $52,080 \pm 5,16$ & abcdefgh & $\mathrm{TiO}_{2}$-Yüksek & $1,16 \pm 0,08$ & abcdefg \\
\hline Ag-Çok yüksek & $52,800 \pm 3,29$ & abcdefgh & Au-Çok yüksek & $1,21 \pm 0,1$ & abcdef \\
\hline ZnO-Çok düşük & $53,500 \pm 4,19$ & abcdefgh & Ag-Düşük & $1,27 \pm 0,08$ & abcde \\
\hline ZnO-Çok yüksek & $53,800 \pm 00$ & abcdefg & $\mathrm{Ag}$-Çok yüksek & $1,34 \pm 0,08$ & abcd \\
\hline $\mathrm{TiO}_{2}$-Çok yüksek & $57,187 \pm 5,03$ & abcdef & $\mathrm{TiO}_{2}$-Çok yüksek & $1,34 \pm 0,05$ & abcd \\
\hline Kontrol & $59,050 \pm 4,12$ & abcde & $\mathrm{Fe}_{3} \mathrm{O}_{4}$-Çok yüksek & $1,37 \pm 0,09$ & $a b c$ \\
\hline Silika-Orta & $59,733 \pm 11,28$ & $a b c d$ & Silika-Çok yüksek & $1,39 \pm 0,05$ & $a b$ \\
\hline $\mathrm{Fe}_{3} \mathrm{O}_{4}$-Orta & $60,666 \pm 3,23$ & $a b c$ & $\mathrm{TiO}_{2}$-Çok düşük & $1,40 \pm 0,25$ & $a b$ \\
\hline Ag-Düşük & $61,522 \pm 2,97$ & $a b$ & Silika-Çok düşük & $1,40 \pm 0$ & $a b$ \\
\hline Silika-Çok yüksek & $64,516 \pm 3,152$ & $a$ & Kontrol & $1,41 \pm 0,11$ & $\mathrm{a}$ \\
\hline FF değeri \& P düzeyi & 2,56 & & F değeri-P düzeyi & & $39^{* * *}$ \\
\hline
\end{tabular}

NP çeşitleri, Kontrol işlemine göre genel ortalama değerler bakımından incelendiğinde FB, KBÇ ve FY değişkenleri üzerinde olumsuz tesir göstermiştir. Sekiz farklı NP çeşidi arasında $\mathrm{TiO}_{2}$ ve Ag NPs'i FB ve KBÇ değişkenlerine, $\mathrm{TiO}_{2}$ ve $\mathrm{Fe}_{2} \mathrm{O}_{3} \mathrm{NPs}$ 'i ise $\mathrm{FY}$ üzerinde uygulanan diğer NP'lere göre olumsuz etkisinin daha düşük olduğu saptanmıştır. Buna karşın, $\mathrm{FB}$ üzerinde $\mathrm{Au}, \mathrm{Fe}_{3} \mathrm{O}_{4}$ ve
$\mathrm{Fe}_{2} \mathrm{O}_{3}, \mathrm{KBÇ}$ üzerinde $\mathrm{Cu}, \mathrm{FY}$ üzerinde ise $\mathrm{Au} N P s^{\prime} i$ en olumsuz tesiri yapmıştır. FY değerine en olumsuz tesiri yapan Au NP $(\% 10,96)$ 'ne göre kontrol işleminin FY'si $(\% 33,3)$ üç kat daha yüksek bulunmuştur. Uygulanan NP dozu arttıkça genel olarak, belirlenen bütün değişkenler üzerinde olumsuz etki artmaktadır. KBÇ üzerinde en olumsuz tesir $\mathrm{Fe}_{3} \mathrm{O}_{4}$-Yüksek ve Silika-Yüksek işlem 
kombinasyonlarında tespit edilirken, FB üzerinde ise $\mathrm{Fe}_{3} \mathrm{O}_{4}$-Yüksek işlem kombinasyonunda belirlenmiştir.

Yayınlanmış bilimsel çalışmalar incelendiğinde; uygulanmış olan NP çeşit ve dozlarının farklı bitki türleri üzerinde değişik sonuçlar verdiği gözlemlenmiştir. NPs'in tohum çimlenmesinden itibaren başlayan bitki gelişim evrelerinde neden oldukları etkinin şekli ve düzeyi oldukça farklı olabilmektedir (Doğaroğlu ve Köleli, 2016). Cinisli ve ark. (2019) Lee ve ark. (2010) atfen, $\mathrm{SiO}_{2} \mathrm{NP}^{\prime}$ lerin ve $\mathrm{Al}_{2} \mathrm{O}_{2}$ NP'lerin Arabidinopsis thalian çimlenmesini ve büyümesini etkilemediğini, ZnO NP'lerin çimlenmesini engellediğini öne sürmüşlerdir. Arslan (2018) Ag ve Zn NPs'in Beta vulgaris tohumlarının çimlenmesi ile sürgün ve kök uzunluğu üzerindeki etkilerini incelediği çalışmasında, yedi seviyesi $(0,5,10,20,40,80,160 \mathrm{mg} / \mathrm{l})$ uygulanan NPs'in düşük konsantrasyonlarında çimlenmenin teşvik edildiği ancak, yüksek dozlarda NP Zn'nın tohum çimlenmesi üzerine engelleyici etkiye sahip olduğu tespit edilmiştir. Kontrol uygulamasına kıyasla düşük dozlardaki NP Ag dozları sürgün uzunluğu ve kök uzunluğu üzerine artırıcı etki yaptığı gözlenmiştir. Buna karşın, NP Zn sürgün ve kök uzunlukları üzerine engelleyici etkide bulunduğu tespit edilmiştir. Larue ve ark. (2014) NPs'in tohuma uygulanmasıyla tohum çimlenmesinde azalma, zayıf-sağlıklı kök-sürgün büyümesine ve daha az evapotranspirasyona neden olabilir ve kök maruziyetinden sonra, köklerin NPs alması fitotoksik ve genotoksik etkilere neden olabildiğini ifade etmektedirler. Ma ve ark. (2010) ZnO ve Zn NPs'nin daha yüksek konsantrasyonlarının $(2000 \mathrm{mg} / \mathrm{L})$ sırasıyla mısır ve çavdar çimlenmesini inhibe ettiğini bildirmişlerdir. Lin ve Xing (2007), kök büyümesinde en etkili dozu $50 \mathrm{mg} / \mathrm{L}$ nano-Zn turp için; $20 \mathrm{mg} / \mathrm{L}$ çavdarda belirlemişlerdir. Ayrıca, Doğaroğlu ve Köleli (2016) marul tohumlarının çimlenme sayılarının NP dozu arttıkça arttığını ve bu artışın özellikle 80 ve $100 \mathrm{mg} / \mathrm{l} \mathrm{TiO} 2$ konsantrasyonlarında gerçekleştiğini, kök radikula uzamasının ise $20 \mathrm{mg} / \mathrm{l} \mathrm{TiO} 2$ ve $10 \mathrm{mg} / \mathrm{l}$ $\mathrm{TiO}_{2} \mathrm{Ag}$ NP dozlarında artış gösterdiğini belirtmişlerdir.

NPs'in çoğu yüksek konsantrasyonlarda bitkiler üzerinde toksik etkilere neden olabilmekte ve toksisite eşiği bitki türleri ve NPs ile değişmektedir (Lin ve Xing, 2007; Le ve ark. 2008). Ayrıca, NPs'in yüzey özelliği fitotoksik etkilerde önemlidir (Yang ve Watts, 2005). Bununla birlikte; Khotet ve ark. (2012) NPs'in bitki çimlenmesini iyileştirdiğini belirtmişlerdir. Birçok çalışmada ise, bitki fidelerinin çimlenme esnasında NPs'e fizyolojik tepkilerini göstermiştir ancak, tohum çimlenmesi ve kök büyümesinin etkisi bitkiler ve NPs arasında önemli ölçüde farklılık göstermiştir (Hao ve ark., 2016).

Bitki gelişimine katkı sağlayacağı düşünülen ve önerilen NPs'den; Ag yüksek doz uygulamasının pirinç bitkisi üzerinde negatif etki gösterdiğini (Thuesombat ve ark., 2014), ancak Sharma ve ark. (2012) hardal bitkisi üzerinde yaptıkları çalışmalarında, fidelerin canlııı faaliyetlerinde ve antioksidan seviyeleri üzerinde olumlu etki yaptığını gözlemlemişlerdir. Hediat (2012) ve Thomas ve ark. (2016) çalışmalarında fasulye, mısır ve çemen türlerinin gelişiminde de pozitif etki yaptığını çalışma sonuçlarında göstermişlerdir. $\mathrm{TiO}_{2}$ nanopartikül uygulamasında ise Samadi (2014) tek yıllık nane bitkisinin çimlenmesinde NP uygulamasının olumsuz etki yaptığını, buna karşılık Doğaroğlu ve ark. (2016) marul bitkisinin çimlenmesinde düşük dozdaki konsantrasyonlarının olumlu etki yaptığını ifade etmişlerdir. Diğer bir çalışmada ise Doğaroğlu ve Köleli (2014) tek yıllık buğday bitkisinde 10 ve $20 \mathrm{mg} / \mathrm{l} \mathrm{TiO}_{2}$ uygulamalarının kök ve gövde gelişiminde pozitif etkiler oluşturduğunu gözlemlemişlerdir. Askary ve ark. (2016) $\mathrm{Fe}_{2} \mathrm{O}_{3} \mathrm{NP}$ yüksek doz uygulamasının nane bitkisinin çimlenme yüzdesinde belirgin bir artışa sebebiyet verdiğini belirtmişlerdir. Silika NP uygulaması için; Sun ve ark. (2016) ve Mohammed ve ark. (2019) tohum çimlenme başarısını artırırığını ve fidecik gelişiminin de olumlu yönde etkilediğini dile getirmişlerdir. Bununla birlikte; Çelikbaş (2019) ve Tan Çelikbaş (2019) yüksek lisans tez çalışmalarında karaçam ve sarıçam türlerinin fidan boyu, kök boğazı çapı ve fidan yüzdesi üzerinde NPs uygulamalarının olumlu etkilerini gözlemlediklerini belirtmişlerdir.

\section{SONUÇ}

Farklı NP çeşit ve doz uygulamalarına ait ormancılık alanında ulusal düzeyde neredeyse hiçbir yayının olmaması nedeniyle gerçekleştirilen bu çalışmanın sonuçlarının diğer orman ağacı türleri için bir altıı oluşturabileceği düşünülmektedir. Ayrıca, çalışmanın sonuçları ile çevremizde konsantrasyonları hızı ıir şekilde artan, pozitif ya da negatif etkileri hakkında çok az bilginin bulunduğu nanopartiküllerin, ormanların gençleştirme süreçleri ile tohum ve fidan üretim çalışmaları üzerinde olumlu ya da olumsuz olası etkileri hakkında fikir vermesi ve ilk araştırma sonuçlarını sunması açısından önemlidir.

\section{TEŞEKKÜR}

Bu çalışma Kastamonu Üniversitesi Bilimsel Araştırma Proje Koordinatörlüğü tarafından desteklenen KUBAP01/2017-11 nolu projenin imkanlarından faydalanılarak üretilmiştir.

\section{KAYNAKLAR}

Aleksandrowicz-Trzcińska, M., Bederska-Błaszczyk, M., Szaniawski, A., Olchowik, J., Studnicki, M. (2019). The effects of copper and silver nanoparticles on container-grown 
Scots pine (Pinus sylvestris L.) and pedunculate oak ( $Q u$ ercus robur L.) seedlings. Forests, 10(3): 269. https://doi.org/10.3390/f10030269

Arslan, M. (2018). Effect of Nano Silver and Zinc on Seed Germination and Seedling Growth of Sugar Beet, The Turkey 6. Seed Congress with International Participation, 10-13 September 2018, Niğde,TURKEY, Book of Proceedings, 121-125.

Askary, M., Talebi, S., Amini, F., Bangan, A. D. (2016). Effect of $\mathrm{NaCl}$ and iron oxide nanoparticles on Mentha piperita essential oil composition. Environmental and Experimental Biology, 14: 27-32.

Azura, M. N., Zamri, I., Rashid, M. R., Shahrin, G. M., Rafidah, A. R., Rejab, I. M., Amyita, W. U. (2017). Evaluation of nanoparticles for promoting seed germination and growth rate in MR263 and MR269 paddy seeds. Journal Tropical Agricultural Food Scince, 45: 13-24.

Cinisli, K. T., Uçar, S., Dikbaş, N. (2019). Nanomateryallerin Tarımda Kullanımı. Yüzüncü Yıl Üniversitesi Tarım Bilimleri Dergisi, 29 (4): 817-831.

Çelikbaş, H.M. (2019). Bazı Nano Partiküllerin Sarıçam (Pinus sylvestris L.) Tohumlarının Çimlenmesi Üzerindeki Etkisi. Yüksek lisans tezi. Kastamonu Üniversitesi, Fen Bilimleri Enstitüsü, Kastamonu.

Doğaroğlu, Z.G., Köleli, N. (2016). Titanyum dioksit ve titanyum dioksit-gümüş nanopartiküllerinin marul (Lactuca sativa) tohumunun çimlenmesine etkisi. Çukurova Üniversitesi Mühendislik Mimarlık Fakültesi Dergisi, 31(ÖS 2): 193198.

Doğaroğlu, Z.G, Köleli, N. (2014). Titanyum dioksit nanopartikülünün buğday çimlenmesine etkisi. ISITES 2014, Akademik Platform. Karabuk, Turkey, Book of Proceedings, 1283-1288.

Du, W., Sun, Y., Ji, R., Zhu, J., Wu, J., Guo, H. (2011). TiO2 and ZnO Nanoparticles Negatively Affect Wheat Growth and Soil Enzyme Activities in Agricultural Soil. Journal of Environmental Monitoring, 13: 822-828.

Fırat, Z. (2020). Beypazarı Kızılçam Kültürleri Gelişimine Nanopartikül Uygulamalarının Etkisi. Yüksek Lisans Tezi, Kastamonu Üniversitesi, Fen Bilimleri Enstitüsü, Kastamonu.

Gürmen, S., Ebin, B. (2008). Nanopartiküller ve Üretim Yöntemleri-1, TMMOB Metalurji Mühendisleri Odası. Metalurji, 31-38.

Hao, Y., Zhang, Z.T., Rui, Y.K., Ren, J.Y., Hou, T.Q., Wu, S.J., Rui, M.M., Jiang, F.P., Liu, L.M. (2016). Effect of different nanoparticles on seed germination and seedling growth in rice. In Proceedings of the 2nd Annual International Conference on Advanced Material Engineering, AME 2016, Wuhan, China, 15-17 April 2016; Atlantis Press: Paris, France, 166-173.

Hediat, M. (2012). Effects of silvernanoparticles in somecropplants, Commonbean (Phaseolusvulgaris L.) andcorn (Zeamays L.). International Research Journal of Biotechnology, 3(10): 190-197.

Kaweeteerawat, C., Ivask, A., Liu, R., Zhang, H., Chang, C, H., Low-Kam, C., Fischer, H., Ji, Z., Pokhrel, S., Cohen, Y. (2015). Toxicity of metal oxide nanoparticles in Escherichia coli correlates with conduction band and hydration energies. Environmental Science Technology, 49:1105-1112.
Khot, L. R., Sankaran, S., Maja, J. M., Ehsani, R., Schuster, E. W. (2012). Applications of Nanomaterials in Agricultural Production and Crop Protection: A Review, Crop Protection, 35: 64-70.

Kundu, S., Adhikari, T., Rao, A. S. (2015). Nanotechnology, Plant Nutrition and Climate Change, Chapter 9 in Climate Dynamics in Horticultural Science, 2, 152p.

Kuzma, J. (2008). Agrifood Nanotechnology: Upsream Assessment of Risk and Oversigt", Center for Science, Technology, and Public Policy Humphrey Institute, University of Minnesota, USA.

Larue, C., Castillo-Michel, H., Sobanska, S., Cécillon, L., Bureau, S., Barthès, V., Ouerdane, L., Carrière, M., Sarret, G. (2014). Foliar Exposure of the Crop Lactuca sativa to Silver Nanoparticles: Evidence for Internalization and Changes in Ag Speciation. Journal of Hazardous Materials, 264: 98106.

Lee, W. M., An, Y. J., Yoon, H., Kweon, H.S. (2008). Toxicity and Bioavailability of Copper Nanoparticles to The Terrestrial Plants Mung Bean (Phaseolus radiatus) and Wheat (Triticum aestivum): Plant Agar Test For Water-Insoluble Nanoparticles. Environmental Toxicology and Chemistry, 27(9): 1915-1921.

Lin, D., Xing, B. (2007). Phytotoxicity of Nanoparticles: Inhibition of Seed Germination and Root Growth. Environmental Pollution, 150(2): 243-250.

Ma, X., Wang, C. (2010). Fullerene nanoparticles affect the fate and uptake of trichloroethylene in phytoremediation systems. Environmental Engineering Science, 27(11): 989992.

Ma, X., Geisler-Lee, J., Deng, Y., Kolmakov, A. (2010). Interactions Between Engineered Nanoparticles (ENPS) and Plants: Phytotoxicity, Uptake and Accumulation Review. Science of the Total Environment, 408(16): 3053-3061.

Miller, J. C., Serrato, R., RepresasCardenas, J. M., Kundahl, G., (2004). The Handbook of Nanotechnology. John Wiley \& Sons, Inc., Hoboken, New Jersey.

Mohammed, M., Elgarawany, M., Al-Saeedi, A., El-Ramady, H. (2019). Application of silica nanoparticles induces seed germination and growth of cucumber (Cucumis sativus). Journal of King Abdulaziz University-Meteorology Environment and Arid Land Agriculture Sciences, 28(1): 57-68.

Rao, C. N. R., Müller, A., Cheetham, A. K. (2005). The Chemistry of Nanomaterials Volume 1, WILEY-VCH Verlag GmbH \& Co. KgaA, Weinheim.

Roco, M. C. (2011). The long view of nanotechnology development: the national nanotechnology initiative at 10 years. Journal of Nanoparticle Research, 13:427-445.

Samadi, N. (2014). Effect of TiO2 and TiO2 Nanoparticle on. International Journal of Plant \& Soil Science, 3(4):408-418.

Sharma, P., Bhatt, D., Zaidi, M., Saradhi, P., Khanna, P., Arora, S. (2012). Silver Nanoparticle-Mediated Enhancement in Growth and Antioxidant Status of Brassica juncea. Applied Biochemistry and Biotechnology, 167(8): 22252233.

Sun, D., Hussain, H., Yi, Z., Rookes, J., Kong, L., Cahill, D. (2016). Mesoporous silica nanoparticles enhance seedling growth and photosynthesis in wheat and lupin. Chemosphere, 152: 81-91. 
Açık Arazi Koşullarında Kızılçam (Pinus brutia Ten.) Tohumlarının Fidan Gelişimi ve Fidan Yüzdesi Üzerine Bazı Nanopartikül Uygulamalarının Etkisi

Tan Çelikbaş, A. (2019). Bazı Nano Partiküllerin Anadolu karaçamı (Pinus nigra Arnold. subsp. pallasiana Lamb. (Holmboe)) Tohumlarının Çimlenmesi Üzerindeki Etkisi. Yüksek lisans tezi, Kastamonu Üniversitesi, Fen Bilimleri Enstitüsü, Kastamonu.

Thomas, R., Jasim, B., Mathew, J., Radhakrishnan, E. (2016). Plant growth and diosgenin enhancement effect of silver nanoparticles in Fenugreek (Trigonella foenum-graecum L.). Saudi Pharmaceutical Journal, 25: 443-447.

Thuesombat, P., Hannongbua, S., Akasit, S., Çadchaçası, S. (2014). Effect of silver nanoparticles on rice (Oryza sativa L. cv. KDML 105) seed germination and seedling growth. Ecotoxicology and Environmental Safety 104: 302-309.
Tunca, E.Ü. (2015). Nanoteknolojinin Temeli Nanopartiküller Ve Nanopartiküllerin Fitoremediasyonu, Ordu Üniversitesi Bilim ve Teknoloji Dergisi, 5(2): 23-34.

URL-1 (2021). https://www.mgm.gov.tr/iklim/iklim-siniflandirmalari.aspx?m=BEYPAZARI (Erişim Tarihi: 12.05.2021).

Yang, L., Watts, D.J. (2005). Particle Surface Characteristics May Play an Important Role in Phytotoxicity of Alumina Nanoparticles. Toxicology Letter ,158(2): 122-132.

Zhu, H., Han, J., Xiao, J., Jin, Y. (2008). Uptake, translocation, and accumulation of manufactured ironoxidenano particles by pumpkin plants. Journal of Environmental Monitoring, 10(6): 713-717. 